\title{
Penyediaan Air Bersih Pada Masyarakat Di Daerah Kampung Waroi Distrik Yantidori Kabupaten Biak
}

\author{
Frans Simbol Tambing, Bodian Davin Panggabean \\ Fakultas Teknik Universitas Cenderawasih \\ Email : ft@ft.uncen.ac.id
}

\begin{abstract}
The availability of clean water sources, especially in the waroi village area has not been adequately optimized by the local government, especially local companies (PDAMs) to serve the level of community needs, for this reason groundwater drilling needs to be done. Ground water is water that is tapped or sucked from underground which is known, both in quantity and quality, to be used as the needs of the community every day. The source of clean water that is used both for washing, bathing and drinking water needs in Waroi village so far is utilizing rain water. The quality and quantity of rainwater is very limited, while the need for clean water for community needs is very high. For this reason, with the existence of deep groundwater drilling, the more or less the need for clean water for the community can be overcome. This service is directly implemented in the field by managing using equipment that is cheap, simple, and affordable and can directly feel the benefits by the waroi village community. The depth of the wellbore is around 75 meters. The distribution of clean water is done by installing a water storage tank (intake) as high as 5 meters above the ground level, then connected with about 5 distribution water pipes that are installed by faucets, so that the community can use water directly every day.In the end, it must be considered how much clean water will be needed and the system used in searching for clean water sources, both manual and conventional.
\end{abstract}

Keywords: Drilling, Quantity and Quality.

\section{Pendahuluan}

Air tanah merupakan sumber air bersih yang paling banyak dimanfaatkan dalam kehidupan manusia.Kebutuhan makhluk hidup di dunia ini tidak dapat terlepas dari air. Bagi manusia sendiri dapat merasakan betapa pentingnya kebutuhan pokok air ini di dalam kehidupan sehari-hari, mulai dari mandi, memasak, mencuci piring, sampai keperluan untuk makan dan minum, semua itu jelas memerlukan air. Oleh karena itu dapat dikatakan, betapa sedih dan sangat menderitanya kehidupan manusia, seandainya

Penyediaan Air Bersih Pada Masyarakat Di Daerah Kampung Waroi Distrik Yantidori 
kebutuhan air dirasakan kurang tercukupi, atau bahkan tidak ada sama sekali. Air tanah yang diperoleh dari sumur bor di kampung waroi ini awalnya merupakan hibah atau bantuan air bersih dari pemerintah kabupaten biak. Tetapi seiring dengan berjalannya waktu, sumur bor di kampung ini tidak berproduksi lagi akibat adanya kerusakan.Kerusakan yang terjadi belum diketahui benar penyebabnya. Untuk itu kami sebagai team pengabdian pada masyarakat mencoba mencari penyebab kerusakan dari sumur bor tersebut dan berusaha mengaktifkan sumur tersebut agar berproduksi kembali, sehingga kebutuhan akan air bersih dapat teratasi kembali.

Berdasarkan kenyataan ini maka perlu dilakukan suatu treacment sistem pemipaan pada sumur dan juga pengelolaan airtanahyang terdapat dalam air sumur bor masyarakat kampung waroi tersebut, sehingga diharapkan airtanah yang semula tidak berfungsi atau mengalami permasalahan, kemudian dapat berproduksi kembali dan dapat dimanfaatkan oleh masyarakat kampung waroi kembali dan kebutuhan akan air bersih dapat teratasi kembali.

Pengabdian ini langsung diterapkan di lapangan dengan pengelolaan menggunakan peralatan yang murah, sederhana, serta terjangkau dan langsung dapat di kerjakan langsung oleh mayarakat itu sendiri. Dimana akan dilakukan penggantian dan pemasangan kembali pipa-pipa sumur bor yang sudah rusak dengan menggunakan pipa paralon atau besi sesuai keinginan masyarakat setempat.

Untuk mengatasi tingkat kekeruhan air akibat proses pengendapan yang berlangsung lama selama ini karena air tersebut tidak mengalir atau tertimbun, diperlukan suatu pengolahan dengan tujuan mengurangi bahkan menghilangkan tingkat kekeruhan air tersebut.

Pengabdian ini langsung diterapkan dilapangan dengan pengelolaan menggunakan peralatan yang murah, sederhana, serta terjangkau dan 
langsung dapat dirasakan manfaatnya oleh masyarakat kampung waroi.Kedalaman sumur bor sekitar 75 meter. Penyaluran air bersih dilakukan dengan cara memasang tangki penampungan air (intake) setinggi 1,20 meter diatas permukaan tanah, kemudian disambung sekitar 5 buah pipa air penyaluran yang dipasang kran, sehingga masyarakat dapat menggunakan air secara langsung setiap hari.

Pada permasalahan yang dihadapi di daerah pengamatan yaitu tingginya kebutuhan akan penggunaan air bersih setiap hari, sementara kondisi air tanah yang terdapat di dalam sumur masyarakat yang dipakai setiap hari kenyataannya tidak berfungsi, sehingga selama bertahun-tahun masyarakat hanya memanfaatkan air hujan sebagai kebutuhan setiap hari. Berdasarkan kenyataan ini dapat di simpulkan beberapa permasalahan yang antara lain:

1. Kerusakan apa yang terjadi pada instalasi sumur bor

2. Bagaimana kondisi air tanah yang terdapat di dalam sumur bor.

3. Bagaimana upaya menyediakan air bersih untuk kebutuhan masyarakat setiap hari.

4. Peralatan dan bahan yang dipergunakan.

Pengolahan air baku adalah usaha teknis yang dilakukan untuk menghasilkan produk air yang sesuai dengan standar kualitas air layak minum. Standar kualitas air yang digunakan meliputi standar fisika, kimia, dan biologi. Untuk memenuhi standar tersebut diperlukan pengolahan fisik, kimia maupun biologi. Teknik pengolahan yang dilakukan disesuaikan dengan sumber air yang digunakan sebagai sumber air baku. Penentuan cara pengolahan juga harus memperhatikan baik buruknya kualitas air baku. Dikenal ada tiga teknik pengolahan air baku ${ }^{1}$ yaitu:

${ }^{1}$ Alamsyah, S., 2006, Alat Penjernih Air Untuk Rumah Tanggga, PT KawanPustaka, Jakarta

Penyediaan Air Bersih Pada Masyarakat Di Daerah Kampung Waroi Distrik Yantidori 
Pengolahan secara fisika merupakan pengolahan sifat fisik air untuk memenuhi standar fisik sebagai bahan baku air minum yang meliputi bau, rasa, tingkat kejernihan, jumlah zat yang terlarut, suhu dan warnanya. Pengolahan air secara fisika dilakukan dengan beberapa cara;

1. Penyaringan merupakan proses pemisahan padatan yang larut dalam air. Pada proses ini, filter berperan memisahkan air dari partikel partikel padatan. Media filter yang sering digunakan adalah pasir, kerikil, ijuk, dan arang.

2. Pengendapan bertujuan untuk memisahkan air dan partikel - partikel padat yang terdapat dalam air dengan memanfaatkan gravitasi. Padatan yang berat jenisnya lebih besar daripada air akan mengendap dengan cara mendiamkan beberapa waktu atau dengan menambahkan bahan kimia untuk mempercepat pengendapan. Bahan kimia yang digunakan untuk mengendapkan partikel padatan adalah koagulan. Koagulan merupakan bahan yang dapat mempercepat terjadinya proses koagulasi. Koagulasi merupakan reaksi kimia yang menyebabkan terjadinya penggumpalan endapan partikel pada dasar penampungan. Bahan koagulan yang sering dipakai untuk menjernihkan air, antara lain kapur, tawas dan kaporit.

3. Absorpsi, merupakan peristiwa penyerapan bahan - bahan tertentu yang terlarut dalam air. Bahan yang digunakan untuk menyerap disebut absorbent. Proses absorpsi dapat dilakukan dengan cara memanfaatkan absorbent sebagai media filter. Absorbent yang umum digunakan dalam proses penjernihan air adalah karbon aktif.

4. Adsorpsi adalah proses penangkapan ion yany terdapat dalam air. Material penangkap ion disebut dengan adsorbent. Adsorbent yang biasa digunakan dalam proses adsorpsi adalah zeolit.

Penyediaan Air Bersih Pada Masyarakat Di Daerah Kampung Waroi Distrik Yantidori 
Pada pengabdian ini, proses penyediaan air bersih di kampung waroi ini hanya lebih menekankan pada pengelolaan sumur bor dalam masyarakat yang sudah mengalami kerusakan selama kurang lebih duabelas tahun, yang mana dilakukan dengan cara pembongkaran dan pengeboran (penyempurnaan) sumur bor tersebut, sehingga dapat difungsikan kembali dan kebutuhan akan air bersih dapat terpenuhi setiap hari. Target yang ingin dicapai antara lain sebagai berikut:

1. Sumur bor dalam milik masyarakat kampung yang selama ini mengalami kerusakan, dapat di fungsikan kembali.

2. Kebutuhan akan air bersih dengan kualitas dan kuantitas yang layak dapat terpenuhi.

3. Masyarakat kampung waroi tidak lagi tergantung pada air hujan sebagai sumber air bersih untuk kebutuhan setiap hari.

Tujuan kegiatan instalasi pipa sumur bor yang dilakukan di daerah kampung waroi ini adalah bertujuan untuk:

1. Untuk mengaktifkan kembali sumur bor masyarakat yang telah lama tidak berproduksi.

2. Untuk penyedian air bersih.

3. Untuk memperoleh kuantitas dan kualitas air bersih yang layak dipergunakan untuk kebutuhan masyarakat setiap hari.

Manfaat kegiatan instalasi pipa sumur bor, yaitu:

1. Dapat menghasilkan air tanah kembali dan layak dipergunakan sebagai kebutuhan sehari-hari.

2. Masyarakat dapat lebih memahami akan pentingnya air tanah sebagai kebutuhan sehari-hari, sehingga meningkatkan kesadaran untuk menjaga air tanah dari berbagai pencemaran lingkungan.

3. Kebutuhan akan air bersih dalam jumlah (kuantitas) yang layak pakai sebahagian dapat terpenuhi. 


\section{Metode}

Metode pengamatan yang dilakukan yaitu dengan mengumpulkan datadata yang tersedia, baik itu data primer, maupun berupa data sekunder seperti pada Gambar 1.

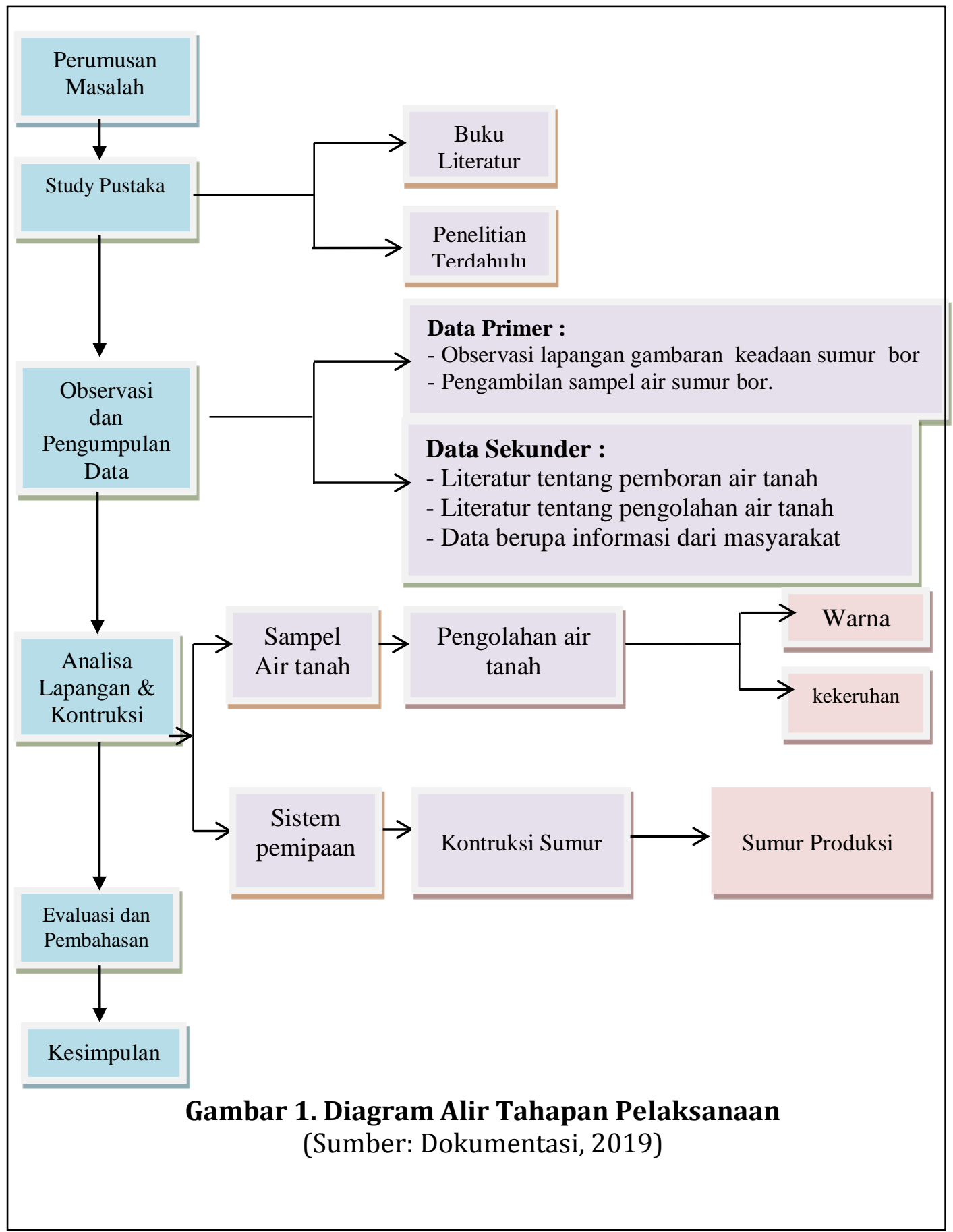

Penyediaan Air Bersih Pada Masyarakat Di Daerah Kampung Waroi Distrik Yantidori

Kabupaten Biak

Frans Simbol Tambing, Bodian Davin Panggabean 
Komunitas sasaran pada pengabdian ini lebih di utamakan kepada kebutuhan langsung oleh penduduk kampung waroi, dimana penggunaan air hujan sebagai sumber air bersih untuk kebutuhan sehari-hari (baik mandi, cuci, dan air minum) belum terpenuhi karena ketergantungan hanya pada sumber air hujan saja, sedangkan air hujan tidak setiap hari turun, sedangkan penggunaan air bersih untuk kebutuhan setiap hari memerlukan jumlah yang cukup besar. Selain itu penggunaan air hujan untuk keperluan air minum setiap hari juga dapat berpengaruh terhadap kesehatan manusia, secara khusus pada masyarakat kampung waroi ini.

Peralatan yang dipergunakan pada proses instalasi dan pengolahan air ini cukup sederhana dan murah, dan bahan-bahannya dapt diperoleh di sekitar daerah tersebut, sehingga secara berkelanjutan, masyarkat kampung waroi ini dapat menerapkannya secara mudah, dan dapat mengatasi secara sendirinya nanti kedepan mengenai instalasi dan pengolahan air secara fisik.

Desain alat, kinerja, serta produktivitasnya dilakukan berdasarkan langkah-langkah berikut ini :

1. Tahap Persiapan alat

Pada tahap ini, kegiatan yang dilakukan yaitu mempersiapkan alatalat untuk proses pembongkaran pipa-pipa sumur bor terlebih dahulu sebelum turun kelokasi. alat -alat yang dipersiapkan yaitu:

a. Material penyaring seperti ijuk dan pasir halus.

b. Peralatan kontruksi yaitu pipa paralon untuk ukuran 4" dan 2', lem pipa, sambungan/ elbow, plat saringan, penutup atas dan bawah saringan.

c. Pompa

d. Kompresor

e. Tempat sampel air tanah 

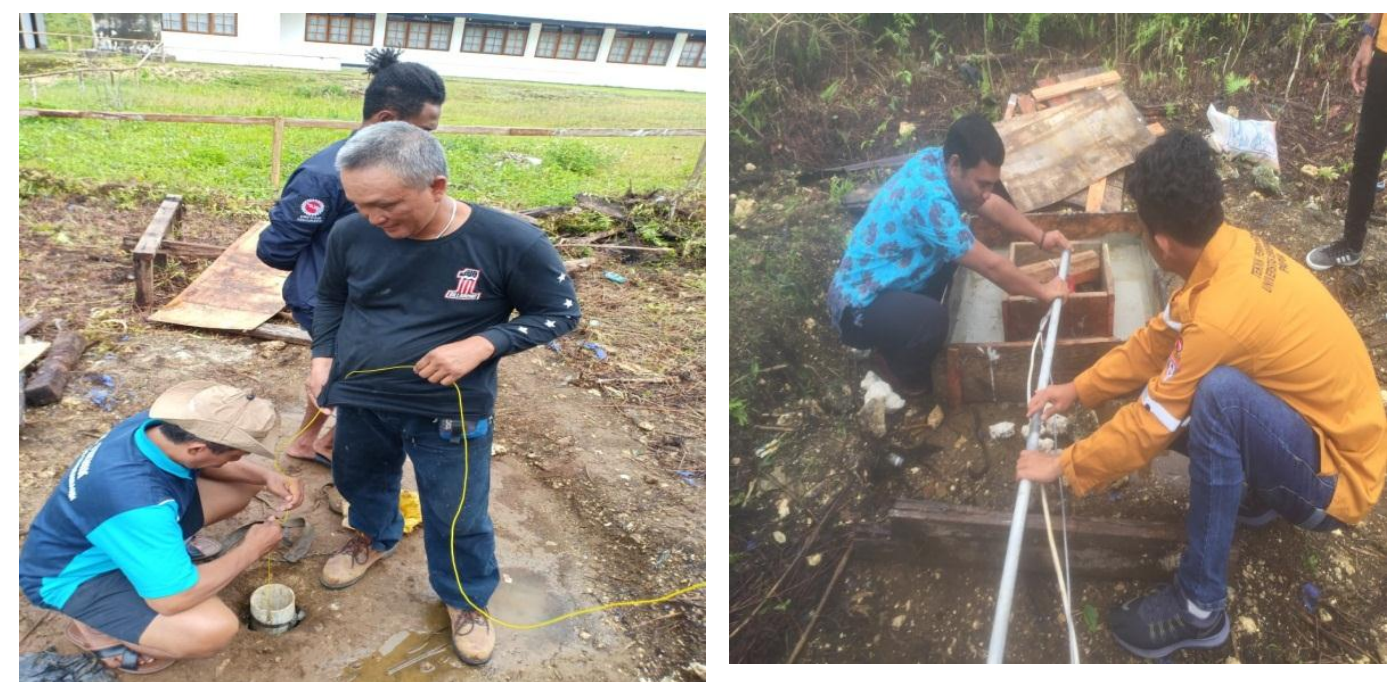

Gambar 2. Lokasi Pengambilan Sampel (Sumber: Dokumentasi, 2019

2. Tahap pembongkaran sumur bor.

Pada tahap ini dilakukan pembongkaran sumur bor dengan cara menarik semua pipa-pipa instalasi sumur bor ke permukaan, kemudian dilakukan pengecekan terhadap kendala atau hambatan atau kerusakan pada semua instalasi sumur bor yang menyebabkan air tanah tidak dapat dipompakan ke atas.

3. Tahap perakitan alat.

Pada tahap ini alat-alat kontruksi sumur bor dan filterisasi akan dirakit langsung di lokasi pengamatan yaitu sumur umum produksi masyarakat kampung waroi yang dipergunakan setiap hari. Dimana pada tahap ini filter diletakkan pada bagian bawah dari pipa jambang (pipa masuk), kemudian dilanjutkan dengan pemasangan pompa ke bagian pipa jambang lalu diturunkan sampai kebawah sumur, kemudian pipa-pipa disambung lagi dengan pipa naik hingga ke permukaan tanah. Selanjutnya dilakukan lagi perakitan untuk pembuatan tempat penampungan air. 
Pembuatan tempat penampungan air ( water tank ) ini dilakukan tepat di atas sumur bor yang telah selesai di perbaiki dan di instalasi kembali. Tingi tempat penampungan air ini sekitar 5 meter dan disambung sekitar lima pipa pada bagian bawah tangki penampungan yang sudah dipasang dengan kran air untuk aliran air ke bawah sehingga dapat di pergunakan masyarakat setiap hari.

4. Tahap proses pengolahan air

Pada tahap proses pengolahan air tanah ini dilakukan proses pengolahan secara fisik. Tahap awal yaitu dengan melakukan water waching dengan cara memompakan air tanah dalam sumur secara terus menerus \pm 1 jam, kemudian pompa dimatikan, lalu pompa di hidupkan kembali 1 jam lalu dimatikan. Langkah pertama ini dilakukan berulang ulang sampai didapatkan perubahan warna air yang semula keruh menjadi jernih.Pada tahap ke dua setelah air terlihat mulai jernih kemudian pompa dihidupkan lagi dan di biarkan air mengalir \pm 4-5 jam sambil di analisa kandungan pasirnya hingga habis. Langkah kedua ini juga dilakukan secara berulang-ulang seperti langkah pertama.

Pada tahap akhir ini air tanah (air sumur) dipompakan kedalam alat penyaring berupa ijuk dan pasir tadi yang sudah dimasukkan kedalam pipa bagian bawah sumur bor dan pompa dibiarkan hidup \pm 10-12 jam, sehingga diperoleh air tanah yang kuantitas dan kualitasnya layak untuk dipergunakan.

\section{Hasil dan Diskusi}

Setelah dilakukan pembongkaran yaitu dengan pengangkatan semua pipa-pipa sumur bor dari dalam sumur ke permukaan, lalu dilakukan pengamatan. Dari hasil pengamatan di ketahui penyebab hambatan yang 
terjadi pada sumur bor selama ini yaitu terjadinya kerusakan pada pompa, sehingga pompa air yang berjenis submersible pump harus diganti. Selain kerusakan pada pompa, juga adanya penimbunan lumpur pada dasar lubang sumur akibat terjadinya kelongsoran tanah pada bagian dinding sumur bor, kemudian juga ditemukan beberapa batang pipa-pipa penyambungan mengalami korosif atau berkarat yang wajib harus diganti.

\section{Kontruksi Sumur}

Penyediaan air bersih dilakukan dengan cara melakukan pemboran air tanah terlebih dahulu karena lubang bor yang lama kemungkinan sudah mengalami kelongsoran pada posisi kedalaman kurang lebih 70 meter. Setelah air tanah diperoleh, kemudian selanjutnya dilakukan pemasangan Casing (bagian selubung) untuk menghindari terjadinya kelongsoran bagian atas atau permukaan tanah yang berada di sekitar lubang bor. Pemasangan casing ini dengan panjang minimal sepertiga dari kedalaman lubang bor. Setelah pemasangan casing selesai kemudian dilanjutkan dengan proses instalasi pemipaan, baik pipa naik, maupun pipa jambang yang disambungkan langsung dengan pompa. Pompa yang digunakan adalah jenis pompa Submersible Pump (pompa selam), yang mana pompa ini diletakan pada bagian paling bawah sumur bor di bawah tanah yaitu dengan cara menyambungkan langsung dengan pipa naik.

Material sumur yang akan dipasang untuk konstruksi sumur bor antara lain terdiri dari :

a. Pipa jambang berdiameter sesuai dengan design sumur dan spesifikasi pompa yang akan dipasang. Fungsi pipa jambang adalah sebagai tempat atau jambang pompa yang umumnya berdiameter lebih besar dari screen, pipa penghantar/pipa buta.

b. Pipa Saringan.Tipe lubang saringan berupa celah gergaji tangan, yang biasa dibuat sendiri. 
c. Reducer untuk menyambung pipa/screen yang berbeda diameternya.

Dengan bahan yang samadengan pipa lainya yang dipasang.

d. Centraliser dengan diameter sesuai pipa/ screen yang dipasang.

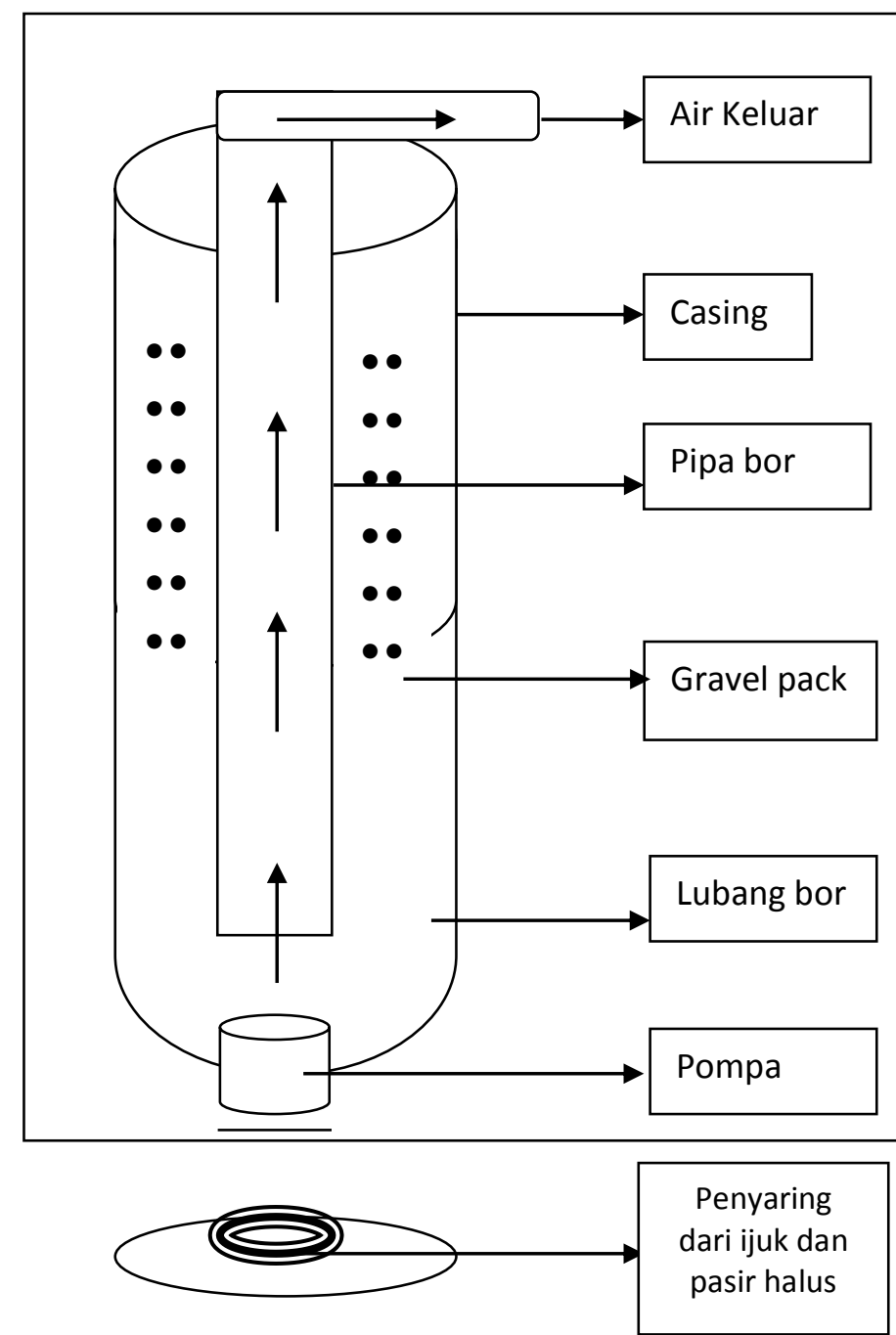

Gambar 2. Skema instalasi sumur bor (Sumber: Dokumentasi, 2019)

e. Pipa kantong lumpur, berupa pipa buta berdiameter sama dengan screen dipasang pada ujung paling bawah konstruksi dan diakhiri dengan tutup bawah sumur. Fungsi pipa ini untuk menampung endapan baik berupa pasir, lempung atau benda lain yang mengendap dan tidak ikut terpompa, suatu saat pada periode operasi pemeliharaan

Penyediaan Air Bersih Pada Masyarakat Di Daerah Kampung Waroi Distrik Yantidori 
secara berkala endapan ini dikeluarkan dengan pencucian sumur atau redevelopment.

f. Bahan penyaring berupa ijuk dan pasir halus.

g. Tutup atas, kunci dan tutup dasar sumur (top cap \& bottom plug).Tutup dasar sumur dapat dibuat dari besi, plastik dan kayu tua yang keras (kayu tahan lapuk jika terendam terus dalam air).

h. Gravel pack, Untuk daerah aluvial Indonesia, umumnya digunakan butiran bergradasi berdiameter antara $8 \mathrm{~mm}-20 \mathrm{~mm}$. bebas dari kotoran dan material karbonat serta material lain yang mudah pecah atau remuk, bentuk butir membulat tanggung sampai membulat.

i. Penempatan gravel pack ke dalam rongga di antara lubang bor dan pipa produksi

j. Semen/mortar digunakan untuk menutup bagian lubang bor atas agar tidak terjadi rembesan dan kontaminasi air permukaan.

k. Bahan bahan penyambung, lem, mur, baut, las.

Setelah pengeboran selesai dan sesuai dengan kedalaman yang dibutuhkan, maka harus dilakukan sirkulasi lumpur lebih kurang 4 (empat) jam atau sampai lubang bor betulbetulbersih dari sisa cutting sesuai dengan yang dijelaskan sebelumnya. Kemudian dilanjutkan pemasangan pipa naik dan pipa saringan didalam lubang bor pada posisi yang tepat sesuai dengan desain sumur yang sudah direncanakan. Pipajambang dan pipa naik serta pipa saringan yang dipasang harus berada tepat pada tengahtengah lubang bor dengan menggunakan centralizer yang terbuat dari besi plat atau bahan lainnya yang akan dipasang setiap 6 meter. Untuk mencapai konstruksi sumur yang baik dan benar instalasi pipa sumur akan dilaksanakan setelah semua bahan seperti pipa jambang, pipa naik dan screen serta gravel pack tersedia dilokasi pekerjaan.

\section{Penyempurnaan Sumur}


Metode yang dipilih untuk dilaksanakan adalah metode sirkulasi air (water flush).

\section{a. Uji Bertahap}

Tujuan dari pemompaan uji bertahap adalah untuk melakukan pemeriksaan terhadap hasil development sumur untuk memperoleh gambaran umum tentang hubungan debit pemompaan dan pengukuran muka air. Oleh sebab itu harus dilakukan pengamatan terhadap debit, kedalaman muka air dan kandungan pasir (tidak melebihi 5 mg/lt) dari air yang dipompa.

\section{b. Uji Debit Tetap}

Setelah permukaan air dalam sumur pulih dari uji penurunan bertahap maka selanjutnya dilakukan pemompaan dengan debittetap selama \pm 12 ( Duabelas ) jam secara terus menerus. Pengamatan terhadap debit pemompaan harus dilaksanakan paling tidak sekali tiap jam sampai debit pemompaan dapat dipertahankan stabil.

\section{Pemasangan Menara Dan Water Tank}

Menara (tower) dalam pekerjaan pengeboran air tanah adalah terbuat dari rangka kayu dengan tinggi 1,20 meter saja karena posisi dari sumur bor sudah berada pada koordinat elevasi yang tinggi. Bahan yang digunakan adalah kayu besi ukuran $5 \mathrm{~mm}$ x $10 \mathrm{~mm}$ sebagai tiang dan ukuran $5 \mathrm{~mm}$ x $5 \mathrm{~mm}$ sebagai pengikat keliling dan silang-silang. Lebar darikaki menara adalah $220 \mathrm{~cm}$ x $220 \mathrm{~cm}$, sedangkan lebar kedudukan tangki air adalah $120 \mathrm{~cm}$ atau sesuai ukuran kedudukan bawaan tangki (pabrik).Landasan dari kaki menara berupa cor semen dengan ukuran 40 $\mathrm{cm} \times 40 \mathrm{~cm} \times 70 \mathrm{~cm}$ (tinggi diatas muka tanah $30 \mathrm{~cm}$ ). 


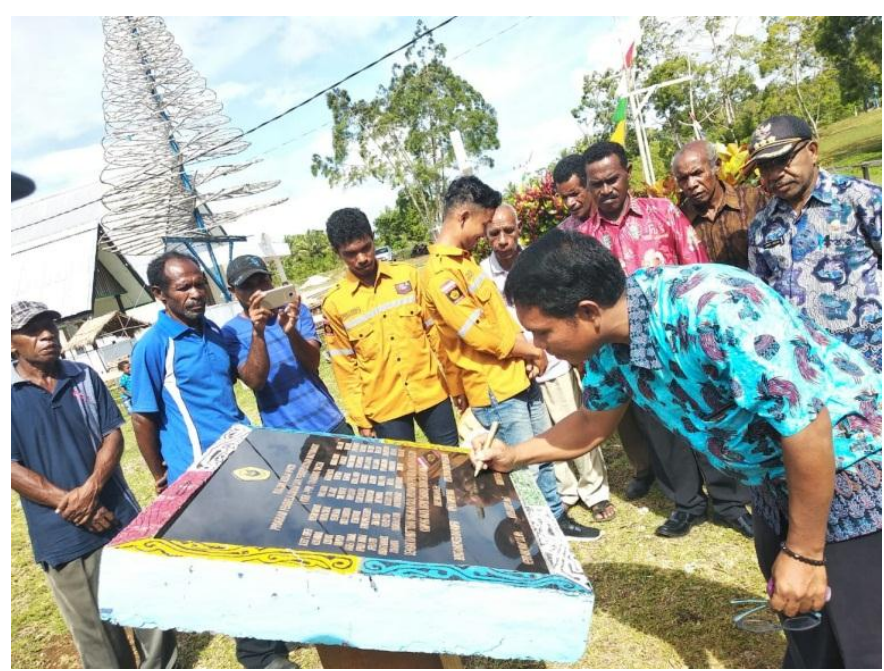

\section{Gambar 4. Penandatanganan Prasasti Hasil Penyediaan Air Bersih}

(Sumber: Dokumentasi, 2019)

Tangki air yang digunakan terbuat dari bahan fiberglass berbentuk tabung yang memiliki kapasitas sebesar 5000 liter.Untuk tempat pengambilan air untuk kebutuhan masyarakat, dilakukan penyambungan pipa dari tangki air menuju ke bawah dengan jumlah pipa pengaliran adalah sekitar empat pipa yang sudah disambung atau dipasang kran air.

Penyediaan Air Bersih Pada Masyarakat Di Daerah Kampung Waroi Distrik Yantidori Kabupaten Biak 
Pada Daerah pijakan pengambilan air bagi masyarakat di pasang coran semen dengan ukuran sekitar 1,5 meter x 2,5 meter dengan tinggi dari permukaan tanah sekitar $25 \mathrm{~cm}$.

\section{Simpulan}

Dari Pengamatan hasil di lapangan, maka dapat disimpulkan sebagai berikut :

1. Hambatan yang terjadi pada instalasi sumur bor yaitu kerusakan pada pompa (submersible pump), adanya kelongsoran pada bagian dinding lubang bor, dan terjadinya korosif atau berkarat pada sebagian pipa isap (pipa naik).

2. Proses pengolahan air tanah secara fisis dengan metode dengan metode sirkulasi air secara terus menerus dan bertahap (water flush) dan juga penyaringan dengan mengunakan iju dan pasir halus.

3. Warna airtanah yang semula terlihat berwarna kuning kecoklatan dan berlumpur berubah menjadi jernih atau tidak berwarna.

4. Diperoleh debit air tanah dengan kuantitas dan kualitas yang layak dipergunakan.

5. Kebutuhan akan air bersih dapat teratasi.

\section{Daftar Referensi}

Alamsyah, S., 2006, Alat Penjernih Air Untuk Rumah Tangga, PT Kawan Pustaka, Jakarta

Appelo, C.A.J., dan Postma, D., 2005, Geochemistry Groundwater And Pollution. 2 nd Editon, Inc, New York.

Bahagiarti, S., 2004, Hydrogeologi Karts, Pusat Studi Karts, Lembaga Penelitian dan Pengabdian Kepada Masyarakat UPN"Veteran" Yogyakarta.

Cheremisinoff \& Paul N.,1995, Handbook of Water and Wastwater Treatment Technology, Marcel Decker Inc., New York. 
Domenico, P.A., 1972, Physical And Chemical Hydrogeology 2nd Ed, John Wiley \& Sons, Inc. New York.

Effendi.H., 2003, Telaah Kualitas Air, Kanisius Yokyakarta.

Sudarto Notosiswojo, Dr.Ir.M.Eng, “ Manual Pemboran Air Tanah “ Laboratorium Hidrogeologi Jurusan Teknik Pertambangan Institut Teknologi Bandung

Soeparmono,1995, "Pedoman Pengembangan Sumur Produksi untuk Pengembangan Konservasi Sumber Air Di Irian Jaya “, Jakarta.

Pedoman Pengawasan Teknik Pelaksanaan Pemboran Air Tanah PT. Kuarsa Hesagon, Bandung

Kaswir Badu, 2002, "Peralatan Pemboran “, Jilid I Cepu 2002, Sumber dari PT. Petrochina International (Bermuda) Ltd. 